\title{
A Semiotic Reading of the East Asian-Canadian Restaging of the Immigrant Experience and Redress in Marty Chan's The Forbidden Phoenix and David Yees's lady in the red dress Rania Mohamed Rafik AbdelFattah Khalil \\ Department of English Language and Literature Faculty of Arts and Humanities, The British University in Egypt (BUE)
} ABSTRACT

The astounding increase in immigration and the rise in intercultural relationships within Canadian society resulted in the last decade in the acceptability of a number of dramatic works by ethnic, immigrant and second generation Canadian playwrights. This paper examines through Ferdinand de Saussure and Charles Sanders Peirce's theory of semiotics the East-Asian Canadian immigrant experience and the journey of redress in two dramatic works: Marty Chan's The Forbidden Phoenix (2010) and David Yee's lady in the red dress (2010). The Forbidden Phoenix and lady in the red dress, address issues related to exclusionary policies against early Chinese immigrants to Canada and historical moments troubled with tension which challenge the audience to examine the legacy of discrimination and prejudices in a nation's community. The two dramatic texts exhibit a complex network of signals not previously examined in research to date and which according to Saussure and Peirce's semiotic theory, may not always be written or uttered, rather, they are presented as signifiers which can be mental or sensory impressions by which meaning is both produced and exchanged. The messages communicated between the performers and the audience in both plays are based on the "ensemble of rules" (Keir 22) embedded within the Chinese-Canadian heritage. The conclusions of this analysis reveal that despite past injustices Canada as a nation can through redress achieve reconciliation and exhibit "cross-cultural solidarity" (Kirby et al.100).

Keywords: East Asian-Canadian theatre, Canadian drama, Semiotics theory, Immigrant experiences, Redress, Railroad drama, Marty Chan, David Yee.

Concepts such as signs, symbols, icons, representations and metaphors are found in our everyday life and interpreting these concepts is a science which aims to show meaning through a shared cultural code or system. Ferdinand de Saussure introduced semiology in his book Course in General Linguistics in1916. The term "semiology" originates from the Greek word "sēmeion" meaning sign (Berger 22); Charles S. Peirce (1991) evolved the term to "semiotics", which is today the 
A Semiotic Reading of the East Asian-Canadian Restaging of the Immigrant Experience and Redress in Marty Chan's The Forbidden Phoenix and David Yees's lady in the red dress

dominant term for the theory of signs involving a sign, its object and its interpretant. Peirce's work has inspired a number of authors to this day: Bertolooti 2017; Eide 2017; Zeidler 2013; Lattmann 2013; Magnani et al.2010; Black 1962. Semiotics is defined as:

... a science dedicated to the study of the production of meaning in society. As such it is equally concerned with processes of signification and with those of communication, i.e. the means whereby meanings are both generated and exchanged. Its objects are thus at once the different signsystems and codes at work in society and the actual messages and texts produced thereby. (Keir 1)

Semiotics in theatre, in general, refers to the communication of meaning between performer and audience during a performance. On the other hand, semiotics in drama stands in reference to "the network of factors relating to the represented fiction" designed for stage representation (Keir 2). This differentiation is not absolute, but is necessary for the analysis in this paper. Before 1931, no substantial progress had been made in the study of theatre semiotics. Two publications from the Czech Republic came out in 1931which fundamentally altered the methodical investigation of theatre and drama; Otakar Zich's Aesthetics of Dramatic Art: Theoretical Dramaturgy and Jan Mukařovský's 'An Attempted Structural Analysis of the Phenomenon of the Actor.' The two publications laid the foundation for the body of dramatic theory published in the 1930s and 1940s by the Prague School Structuralists. Based on Saussure's framework of general semiotics, Prague structuralism linked a material signifier with a mental signified in order to describe "theatrical signs and sign-functions" (Keir 5). According to the above, Winfried Nöth (2018) and Jan Mukařovsky (1934) argue that a theatrical performance is a "macro-sign" it stands as a whole semiotic unit; it is the signifier (Keir 5). The audience's "collective consciousness" is the signified where communication of meaning is transacted as a result of the performance's total effect (Mukařovsky 5). Later semiotic analysts, in contrast to Mukařovsky's approach, believed that for the "unified textual whole" to allow the audience to become the ultimate makers of their meanings, there needs to be a breakdown of the "network of semiotic units belonging to different cooperative systems" (Keir 5). The encoding and decoding of the messages communicated between the performer and 
the audience is normally based on the "ensemble of rules" familiar to both, ultimately holding either a collective or individual meaning to each signal transmitted (22). Signals according to Saussure and Peirce's semiotics theory, may not always be written or uttered, rather, signifiers can be "mental impressions made on our senses by a certain 'thing.' It is our perception, or how we view this 'thing,' together with the sound system of our language that creates the two-part mental linguistic unit ... referred to as a 'sign"' (Lanir).

Winfried Nöth (2018) clarifies that according to Peirce (1904) and given that signs and representations are synonymous "thoughts and mere ideas are signs too" when they conjure a feeling, prompt an action or thought (9). He further points out that both signs and representations, together, are termed "representamen" (9). The interpretation process of the sign is a translation of the sign "into another sign in which it is more fully developed" rendering it more revealing than the sign itself (Peirce 594). Building on this, Nöth (2018) explains that a sign can be both an icon and a type. Along the same line of thought, Rosenblueth and Wiener (1945) and Max Black (1962) suggest that signs can be formulated in words. Further elucidating on Saussure and Peirce's notion of signs, Berger (2014) highlights that meaning derived from signs, symbols, models, types, and metaphors is dynamic; hence, it can be concluded that meaning of codes and signs also differ from one culture to the other because meanings are formed within a society based on its norms, ideas and values. A meaningful code, between the signifier and the signified is accordingly created showing "details not visible to the naked eye" (Nöth 18). However, despite this meaningful code, Nöth (2018) emphasizes that "no Sign is absolutely precise" (18). In summary "semiotics is the study not only of external, but also of internal or mental signs" by which meaning is both produced and exchanged (18).

Within this semiotic theoretical framework where theatre performance is considered a "macro-sign", two East-Asian Canadian plays produced in 2010 will be examined: Marty Chan's The Forbidden Phoenix and David Yee's lady in the red dress (Keir 5). Both plays come under the sub-category of railroad plays which stage representations of the early Chinese immigrant experiences in Canada and highlight the painful negotiation process for redress. Both plays in a broad sense are rehearsals of the intercultural relationships between East Asian Canadians and Anglo-Canadians where the confrontations and renegotiation of relationships can be read as vital for meaningful redress and the wellbeing of Canada as a nation. Marty Chan and David Yee, employ a semiotic 
A Semiotic Reading of the East Asian-Canadian Restaging of the Immigrant Experience and Redress in Marty Chan's The Forbidden Phoenix and David Yees's lady in the red dress

system in their plays that aims to communicate difficult and intricate issues of the past to new generation Chinese-Canadians. The encoding and decoding of the messages and "mental impressions" (Lanir) transacted to the audiences add to the overall theatrical experience and emphasise the intrinsic Chinese culture inherent in Canadian history which has often been overlooked. By reviving Chinese-Canadian heritage and unearthing crucial truths that have shaped the lives of many Chinese, both Chan and Yee present unique dramatic works that transcend local culture and resonate with the experiences of many around the world today.

Over the past decades, Asian Canadian theatre has been a "popular practice of cultural intervention into fractured and violent social realities" (Vellino 93). In a personal interview in May 2018, Marty Chan explains that East Asian Canadian theatre in the 1970s and 80s did not exist. Mainstream theatre in Canada did not have a mandate to promote cultural diversity and tended to avoid producing plays of ethnic origins. The first instrumental Canadian company that promoted cultural diversity in theatre in the late 80s and early 90s was the Cahoots Theatre Project. Consequently, East Asian Canadian playwrights were able to find a home for their thought provoking dramatic works. Later, other theatres like fuGEN Theatre formed partnerships with mainstream companies which in turn, brought the plays to the attention of mainstream audiences. The most notable literature in this sub-genre are Xiapong Li's (2007) Voices Rising: Asian Canadian Cultural Activism and Ric Knowles and Nina Lee Aquino's fu-GEN Theatre Company conference proceedings (2011) Asian Canadian Theatre: New Essays on Canadian Theatre. Earlier successes include Winston Kam's play Bachelor Man (1987) which was the first East Asian Canadian play produced in Canada. The second most notable play was by Chinese Canadian Betty Quan Mother Tongue (1996) followed by Korean Canadian playwright MJ Kang's play Noran Bang (1999) and Marty Chan's Mom, Dad, I'm Living with a White Girl published in 2001. The best known and most successful recent East Asian Canadian play in Canada is Kim's Convenience (2012) by Korean Canadian playwright Ins Choi. The play was developed as an independent production at the Toronto Fringe Festival and was later adopted by the theatre Soulpepper. The play has recently become a national success as an adapted television series on CBC. 
In 2014, the Canadian Association for Theatre Research debated matters related to theatre and immigration in Canada focusing primarily on the role played by the immigrant in holding up the mirror to the nation, the longing for a sense of national community and the extent to which the theatre helps the voice of the immigrant reach a diverse audience. The attempt at retelling the "counter-history" is considered vital for Canada's growth as an emerging nation (Chang 130). East Asian Canadian theatre accordingly, in time, had become an integral player in depicting the history and identity of the "real nation" (Filewod 10). Marty Chan explains that "in 2018, East Asian Canadian theatre has come a long way from the early days when I [he] tried to break in as a playwright. We have a deeper talent pool for actors and a more diverse audience to support the plays" (Interview with Marty Chan, 2018).

Dramatic texts like The Forbidden Phoenix and lady in the red dress which address issues related to exclusionary policies against Chinese immigrants and historical moments troubled with tension, challenge the audience to examine the legacy of discrimination and prejudices in a nation's community. At the same time, these two plays address the importance of reconciliation for past humiliations of early Chinese settlers in Canada. This study also sheds light on understanding the complexity of the psychic displacement of the host nation. The success made by Chan and Yee as East-Asian Canadian playwrights in adding to the repertoire of Asian Canadian theatre and more specifically Canadian theatre, is reason enough to spark an interest in examining their work. Existing published research on The Forbidden Phoenix and lady in the red dress has mostly focused on the dramatic works as railroad plays. There is currently no published literature which examines the plays' sign system based on Ferdinand de Saussure and Charles Sanders Peirce's semiotic theory, although the plays come under the sort of work that lends itself to semiotic scrutiny. For this reason, The Forbidden Phoenix (2010) and lady in the red dress (2010) prove to be important and timely dramatic texts and performances that are worthy of examination.

Lorendana Salis (2010) and Ronit Lentin (2002) believe that for Canada there exists "an official version of ... [the] nation with concomitant notions of cultural and national identity [which tend to promote] exclusive racial ideals" (Lentin 43); they also believe that the current arrival of new immigrants is a reflection of the nation's past (Lentin 44). Marty Chan's and David Yee's plays uproot the unhealed traumatic experiences of the nation through a fictional elsewhere and examine some of the push factors that drive immigration. The content of 
A Semiotic Reading of the East Asian-Canadian Restaging of the Immigrant Experience and Redress in Marty Chan's The Forbidden Phoenix and David Yees's lady in the red dress

the two dramatic works under study touches upon important issues faced by many immigrants around the globe today. Many people are being forced to leave their homes, their families and communities as "the land they live on is no longer capable of sustaining them" (Gilodo \& Sangalli 3 ). It is this recent flood of migration across continents that make this topic one of great urgency.

A semiotic reading of Chan's dramatic text The Forbidden Phoenix and David Yee's lady in the red dress is the key to deciphering the hidden mental and material signs pointing to the painful past of early Chinese immigrants to Canada and their struggle against racism, humiliation and discrimination embedded in these plays. Chinese-Canadian playwright, Marty Chan was the first in residence playwright at the Citadel Theatre. In 2016, he was named one of the top twenty-five most influential artists by Alberta Foundation for the Arts (Chan, 2018). Having experienced the life of an immigrant family first hand, the experiences which Chan depicts in The Forbidden Phoenix (2010) are real. The award winning play reflects back on one of the darkest periods in Canadian history, giving a glimpse of the experiences of the early Chinese Canadian Pacific Railway (CPR) workers in the late 19th century. More than any other government infrastructure, the (CPR) had come to signify "repression, monopoly ... [and] exploitation" (Berton 6). Through a reductionist technique, the immigrant experience is laid out to the audience as a simple narrative of a father, Sun Wukong, who must leave his son, Laosan, in China, in order to search for financial prosperity in British Columbia, Canada. Along his journey, Wukong realizes that he lives in a complicated new world where people are being exploited and that he has a duty to the new land as well as a duty towards those he has left back home (Gilodo and Sangalli).

The Forbidden Phoenix, simulating a rich Peking opera, is a play of two acts which stands as a whole semiotic unit to tell the story of the "irresolvable tension between the drama of arrival and the tragicomedy of the encounter between the new immigrant and the host country" (Meerzon 185). The "hybrid Chinese Opera conveys a mythical story with historical relevance" (M. Chan, About Marty Chan). Composed of a complex network of interconnected signs, it communicates a saga of discrimination through the use of mask, dance, music, colour, martial arts, cultural codes and gestures. As the play unfolds, these same signs 
send a message of hope for reconciliation. The play's signs system creates a "mental culture" which helps the audience interpret the painful metaphorical journey of a nation from alienation to reconciliation (Posner 16). The opening lines of the play begin with "The World: In this stylized world, metaphoric images replace naturalistic settings. A fusion of Chinese opera and Western musical theatre allows the performers to create a landscape mostly with words, gestures, and props" (Chan i). Embedding the Chinese mythological character, Monkey King (Sun Wukong) into the play's modern framework, gives the play an additional layer of meaning, at least for those who are familiar with the traditional Chinese narrative. Those unfamiliar with the fictional character find it difficult to follow the cultural code of the play and see Monkey King (Sun Wukong) as "an anthropomorphic character within a Canadian context" (Chang 18). Sun Wukong, is an iconic figure in Chinese mythology. Chan borrowed the mythical character and merged it with the idea of Wu Cheng'en's sixteenth century novel Journey to the West and the super hero Monkey King. In the original myth, Sun Wukong (Monkey King) is the ruler of a tribe on earth. When he learns that his tribe is starving, he sets off to search for food by venturing into Forbidden Mountain, a symbolic reference to Gumshan, the Chinese name given to the West Coast of British Columbia. Told through the eyes of the early Chinese railroad workers, the play highlights their experiences to "dispute the official historical account that is preserved in imperialist [Anglo-Canadian] texts which deny the existence of racial discrimination and exploitation (Gilbert and Tompkins 12). The play also stands as a whole semiotic unit to tell the story of the "irresolvable tension between the drama of arrival and the tragicomedy of the encounter between the new immigrant and the host country" (Meerzon 185). The challenge for Chan as an East Asian Canadian playwright was "... to blend two worlds, two cultures, and two styles of theatre" (Gilodo \& Sangalli 7).

General Manager William van Horne who oversaw the operations of the Canadian Pacific Railroad in 1882 (Regehr) is represented in the play as Horne. He is described in the stage directions as a man of formidable stature; his fierce character is reflected in his face painting as a majestic warrior standing for greed, capitalism and false empathy: "I am Horne, engineer, Architect of everything here, From the gao lou that stretch to the sun, To these tracks where the future will run" (1.3.19). Horne discriminates against Sun Wukong and classifies him and other immigrant workers as $k u l i$ (lower class workers). He uses the Chinese workers and zha yao (explosives) to destroy the Phoenix's nest and blow 
A Semiotic Reading of the East Asian-Canadian Restaging of the Immigrant Experience and Redress in Marty Chan's The Forbidden Phoenix and David Yees's lady in the red dress

up parts of the Forbidden Mountain to make way for the new railroad tracks. The interactions between Sun Wukong and Horne, revive past tensions, evoke a sense of displacement and reflect the instability of the host nation "... Ah yes, another $k u$ li. The others were confused at first, but they soon learned their place... which is on the ground" (20). The Library and Archives Canada website documents this hardship inflicted on early Chinese immigrants stating that " $[\mathrm{t}]$ he Chinese workers...were given the most back-breaking and dangerous work to do" (History Building the Canadian Pacific Railway). More pertinent to this analysis is the effect of racial discrimination on Asians living in North America, mental health research shows that discrimination can trigger stress and cause socioeconomic dispossession leading to anguish (Krieger). Stage directions in The Forbidden Phoenix, Act II, Scene I depict Sun Wukong sitting in the woods as "a beaten man" (Chan 41). Retreating into the woods, he drinks a liquid from a jug to help him forget his son. The "psychic manifestation of the self" in this scene is metaphorically depicted as a jug (Courtney 209). The referent, prompts the audience to identify the jug as a symbol of the emptiness Sun Wukong feels: "Today, I seek no more tomorrow / The Monkey King gives up his crown / If I could only find my way back home / Why did I ever have to come here, my son / My son, what have I done" (Phoenix, 2. 1. 42). The website "Legal Struggle of Equal Rights for Chinese Canadians" documents the restrictions passed on Chinese immigrants which caused them to leave behind their families: “... every person of Chinese origin shall pay into the Consolidated Revenue Fund of Canada, on entering Canada, at the port or other place of entry, the sum of fifty dollars" (MTCSALTC - The Metro Toronto Chinese \& Southeast Asian Legal Clinic - Government of Canada). The Chinese Head Tax levied on Chinese immigrants between 1885 and 1923 reached up to $\$ 100$ then soared up to $\$ 500$ forcing immigrants to leave behind their spouse, children and the elderly (A. Chan). In an overly simplified manner, Chan summarises, the underpinning issues of immigration in the following line by Sun Wukong: "So I'll stay for another day" (Phoenix 1.1.4). Realising that he must stay on, Sun Wukong defies the challenges of existing in a third space. Homi Bhabha (1990) argues that the space in which one can see a mixture of what is unfamiliar and what is familiar, is the third space on which the immigrant's identity is reevaluated in terms of the self and the other.

In The Forbidden Phoenix, Iron Dragon signifies the CPR train system and "railroad mania" (The Railroad Network). Under Horne's control 
Iron Dragon represents capitalism; it is described as a "creature of mythic proportions" and has "an all-consuming hunger" (1.3. 20). The CPR was perceived by many as a "territorial conquest" (Marx 186). Despite being a sign of progress and advancement, the CPR had subsequently damaging effects. Horne assuming colonial power orders the Chinese workers to "Kill the creature [Phoenix] and open the way to Iron Dragon..." (1.3. 20). Horne's instructions to kill the creature, referring to Phoenix the guarder of Forbidden Mountain, is a signal of destruction of all that is native and natural to the land. Consequently, Sun Wukong and other Chinese workers are the agents by which the Canadian dream will be realised: "So I'll lay tracks to your dream /I'll blast through the creature's shield / I'll free Iron Dragon /So we can close our deal (24).

Ann D. Zabel (2001) examines the representation of trains in twentieth century literature; within the framework of her discussion, Iron Drag on as a representation of the railway can be alternatively decoded as a signifier of the psychological conflict which Sun Wukong experiences as he reflects on the notion of nation building, his longing for home and the need to belong. Peter van der Veer (1995) argues that the image of the train (Iron Dragon) is "the desire for change and movement," it is also a compounded image of the "enigma of arrival" and what it brings on to the individual: a "desire to return to what one has left" behind (4). Hence, Iron Dragon is significantly linked to the alterations associated to Sun Wokong's adaptation process in the host nation. The representation is manifested first in his act of departure from a familiar point (China) and the need for continuity into the future signified by Iron Dragon (the train).

Building further on the metaphor of symbolic journeys and with further reference to adaptations from Chinese opera, in Act I, Scene II, Sun Wukong and his son, Laosan walk in circles on the stage. Chan explains that "in Chinese opera, the way to convey a long journey is to walk in circles" (Interview with Marty Chan, 2018). The stage characters through physical movement in a "semiotic order" signify "transcultural travel" and summon mental images of the allegorical journey from Jung Guo to Terminal City (Veltrusky et al. 136; Rojas 334). Chan clarifies that "the choreographers created their own mini-visual stories with the movement of the play" (Interview with Marty Chan, 2018). Their bodies being an extension of the symbolic communication on the stage, they invite the audience to decode the signs and become fully engaged in reading the characters, experience the setting, feel the music and empathise with the inner sensations of the persecuted peoples of the past. Chan additionally points out that "the singing in The Forbidden Phoenix carries the heart of the play in a way that the text can allude to, but not 
A Semiotic Reading of the East Asian-Canadian Restaging of the Immigrant Experience and Redress in Marty Chan's The Forbidden Phoenix and David Yees's lady in the red dress

hammer home in the same way that music does" during a performance (Interview with Marty Chan, 2018).

In addition to having been published as a play text in 2010, The Forbidden Phoenix is a musical which was performed in 2011 by Citadel Theatre. As such, it is presented in two types of dialogue differentiated through font; regular text for speech and italicised font to suggest that the dialogue is sung: "the lower notes are used for storytelling and setting the scene, the medium notes for expression and the higher notes for exclamation. This mirrors what often happens in real life" (Streeton and Raymond ). The most disturbing emotions in the play are dealt with through music and song. Musical communication is as a complex matter (Veltrusky et al. 135). Regarded as the "originator of the communication" between the audience and the performance, music determines the experiences of the audience ensuring that "every interpretation is unique" (135-6). More specifically, the music stimulates empathy in the audience. Composer and lyricist, Robert Walsh, shares his experience in trying to find the right blend of Chinese and Western sounds for the music in The Forbidden Phoenix:

One element of Chinese Opera that plays an important part in The Forbidden Phoenix sonic landscape is the use of percussion in the role of commentator, punctuating and accenting the dialogue and movement of the characters. In particular, the use of wood blocks, Chinese gongs (that change pitch when you strike them), and low sounding drums, are called upon most frequently, and figure quite heavily in the fight scenes. (Gilodo \& Sangalli 5)

Both the music and the singing in The Forbidden Phoenix, hold a strong element of theatricality which communicates socially constructed signs to the Chinese - Canadian audiences based on the classifications with which their society interprets itself and its reality (Kowzan 32-33). Symbolic elements in the play such as the dynamite (zha yao), Chinese turnip patty (law bak go) and the moon cake, create the cultural context which helps the audience establish a "link between the sign and the situation" both psychologically and in a material sense (Veltrusky et al. 144). Peirce (1991) believes "intelligent consciousness" (239) is required on the part of the audience in order to achieve this mental representation intended by the performer, playwright and the composer. At the same time, the communal experience of the musical allows the audience to react 
collectively to the performance as they engage simultaneously with the costumes, masks, props, language (pin yin) and gestures producing "a latent element of inter-subjective communication" (Veltrusky et al. 136).

The cultural and linguistic elements evident in The Forbidden Phoenix through the use of Chinese language indicates the playwright's heightened awareness of how language as a signifier and as a semiotic system can play a major role in affecting the reception of meaning by the audience. Considered within the Sapir-Whorf theory of the influence of language on thought and perception, this implies "that the speakers of different languages think and perceive reality in different ways and that each language has its own world view" (Al-Sheikh Hussein 642). The use of pinyin (Chinese language sound spelled in English) in The Forbidden Phoenix adds a significant dimension to the play by laying a cultural foundation that shapes the ideas and "guide[s] the [audience's] mental activity, ... analysis of [their] impressions, [and the] synthesis of [their] mental stock" (Al-Sheikh Hussein 643). The play is dotted with Chinese words: " $b a$ ba (ba BA): Daddy; ching ee (ching yee): A duty to respect nature; congee (con gee): Rice porridge; gao lou (g'ow low): Towers; Jung Guo (Joong Gwo): The Middle Kingdom. China; kowtow (cow tow): To get on one's knees and bow; $k u$ li (coo-lee): A lower class worker; and mai lu chien (my loo chen): A toll; moon cake: A sweet Chinese pastry filled with red bean paste and cooked duck egg yolk. Chan includes a glossary at the back of the dramatic text" (Chan71). The audience in a performance would not necessarily have been provided with the glossary or English translation which indicates that either the target audiences are familiar with the context or that Chan is addressing an Asian-Canadian, Chinese speaking demographic. This however, does not detract from the play's universality as it addresses the globally spread underlying problems of immigration and discrimination.

In addition to the pinyin, cultural representation adds a layer of complexity to the simple structure of the play. Additional borrowing from Chinese opera is evident in Chan's use of gestures, masks and colours. Gestures in theatre have always been looked upon as a meaning-making system; a sign which communicates to the audience the character's role, mood and reason behind the action (Lutterbie). The repetition of a particular gesture renders it as a sign that is interpreted by the audience because of their shared culture or experiences. The frame work on which Chan operates in order to communicate with the audiences is the experience of the early Chinese immigrants who built the CPR. Another foundational principal which complements the use of gestures in the play is the use of masks. In Chinese opera, masks play an important role. Characters/performers project emotions through the facial expressions 
A Semiotic Reading of the East Asian-Canadian Restaging of the Immigrant Experience and Redress in Marty Chan's The Forbidden Phoenix and David Yees's lady in the red dress

depicted on their masks as well as by the use of specific colours. Those familiar with the coding of colours in Chinese art can easily identity characters and determine the role they play in a performance based on the colour of the mask. In the opening scene of the performance, Sun Wukong appears with the traditional Chinese opera white- face paint. The white mask is a reference to the three Kingdoms of the warlords of the Eastern Han Dynasty and is often a symbol of craftiness. Horne is poignantly represented by a blue/black mask. Blue is an extension of the colour black, representing fierceness or slyness (Vision Times, 2017).

Laosan on the other hand, is introduced as a tragic clown; an archetypal character adopted from Chinese opera. The first part of his name "Lao" is common for male characters in Chinese Opera meaning young man. His clowning subdues the somber atmosphere of the play and is described by his father as "A ray of sunshine with cauliflower ears" (Phoenix 1.4. 24) and by Empress Dowager a "clown" (1.5. 32). Phoenix, a representation of the natural landscape, is clad in subtle hues of red silk cloth, a reflection of her loyalty, protectiveness of nature, spirituality and fight for justice against Horne. Her silver and gold mask represents her as a supernatural being (Vision Times). In this regard, the role of the mask transcends the function of representation. The conative meaning of the mask results in an unspoken interaction between the performer and the audience; the meaning is communicated through an expression or an image inspiring horror, indignation, or admiration. Veltrusky et al., (2012) point out that the combination of colours and the choice of words have conative meanings with referential repercussions on the audiences' interpretation of the performance and a strong capacity to guide their emotions.

Moreover, Chan's selection of Sun Wukong or Monkey King as the protagonist for his play, immediately establishes the cultural context for the audience. The heroic Chinese mythical figure promises adventure, challenges and victory, but also stands as a strong signifier of heritage and national pride. He is symbolic for the Chinese Canadian identity which came about as a way for the early Chinese immigrants to assert "their Canadianness in the face of racist discourses" (Stanley 109). According to Stanley (2007) "in proclaiming this new identity, they did more than combine two fully formed previously existing identities" (109). Stanley (2007) goes on to further explain that "while both Canadian nationalism and Chinese nationalism supplied the ingredients for this new identity, the term "Chinese Canadian" articulated something completely 
new" (110). Assimilating into a third space (Bhabha, 1994) requires a recreating of identity, and consequently leads to hybridity. Bhabha (1994) recognizes this as an advantage where the third space "initiates new signs of identity and innovative sites of collaboration and contestation" (1). Ankie Hoogvelt (2001) builds on Homi Bhabha's concept of hybridity and defines it as "a kind of superior cultural intelligence owing to the advantage of in-betweeness, the straddling of two cultures and the consequent ability to negotiate the difference" (Hoogvelt 158). Sun Wukong "occupies a paradoxical status ... representing on the one hand, a quintessential icon of mutability and, on the other hand, a paradigm of cultural continuity" (Rojas 334). Act I scene I, opens with Sun Wukong introducing himself as "I am Sun Wukong, the Monkey King, and this is my story" (Chan 3). Scene III marks the start of Sun Wukong's new existence "The West is a strange place, but not terrible. Maybe we could make a home here. (A scream) Or not" (1.3. 18).

The Forbidden Phoenix is partly set in Jung Guo a rural area in China. Most of the railroad workers recruited by labour contractors immigrated from the Guandong province: "These counties suffered from extreme poverty and civil unrest.... Desperate for work, workers from this part of Guangdong boarded ships for [Canada] and other parts to support their families (Standford University ). These difficulties are sung in the play by Sun Wukong: "On the road, I'm forever a stranger / On the road, I'm always in danger / Never trust the ones with smiles, /They'll steal your soul" (1.1.4) At the same time, the Chorus speaks to the audience of the harsh living conditions in the Chinese village: "Where I come from /The rice bowls are empty / Where I come from / Friends kill for congee / Where I come from / Desperation is reality" (1.1.3). Laosan, left behind in China, experiences similar symptoms of despair as a result of his father's absence: "Watching the river run / My fears have just begun / That you'll follow the river / And not come back this way" (1.2. 16). Inevitably, Loasan must adapt to the loss of an economically active family member in a sending community which rarely attends to the problems faced by family members left behind as a result of the immigration process. Laosan in the play is however taken under the patronage of Empress Dowager, a dictator. The Empress hoards the profits and the crops of rice for herself and tolerates no opposition to her rule. At a later stage in the play, she forces Laosan and her subjects to say "Our parents may love us, but not as much as Empress Dowager" (2.4. 49). The image of Dowager protecting Laosan from his father in Act I, Scene V is conjured from Chinese history where "teenagers became the Red Guard, a fanatical army who saw Chairman Mao Tse-Tung as a paternal figure" and in his name committed horrible acts (Interview with 
A Semiotic Reading of the East Asian-Canadian Restaging of the Immigrant Experience and Redress in Marty Chan's The Forbidden Phoenix and David Yees's lady in the red dress

Marty Chan, 2018). The detrimental effects of being left behind by the immigrant family member despite the economic benefits are sung by Empress Dowager: "Come with me, don't wait for your daddy / That man abandoned you / For this he will be sorry /Forget your father, little boy / My love will protect you and bring you joy" (1.5. 34). Empress Dowager's words signify a complete cultural break from the mother nation.

In Act I, Scene II, Sun Wukong's physical and emotional journey is symbolized by entering through a waterfall which represents a portal between China and Canada. The water sign in the play is first introduced as a river and then as a waterfall. The order in which the sign is introduced is significant. According to Jungian therapy, a river is symbolic of an unconscious emotional and spiritual journey; a departure from a previous life and the advancement towards a new one. Sun Wukong is depicted at the start of the play near Pearl River; and later standing beneath the waterfall signifying an act of rebirth (Sherridan). On the other hand, from a Freudian perspective, the waterfall can be interpreted as the unconscious psychological barriers (Hall) which Sun Wukong must face in order to integrate in the host nation. Sophie Gilbert's (2016) analysis of water symbolism reinforces these interpretations: "Water has everything to do with change - in virtually every culture it's a symbol of change." Laosan's reluctance to let his father pass to the other side of the waterfall is an indication of his fears of the intense change that is about to befall his circumstances without his father's presence in his life: "This waterfall can only lead to a bad place. ... You can't be sure there's something better on the other side" (Phoenix 1.2.15). The reuniting of the father and son at the end of the play stands not only as a representation of family bonding between old and future generations, but is primarily a signification towards the idea of reconciliation between the past and the present. Despite the Chinese framework, Chan universalizes the play as an immigrant narrative with which many around the world would resonate.

In a similar manner to Marty Chan, co-founder of fu-GEN theatre company, Chinese-Scottish and Canadian born playwright, David Yee, plays an active role in the Asian-Canadian theatre community. His dramatic text lady in the red dress (2010) is a two time award winning play. The play is a "modern day noir" (Toronto Theatre Database); like The Forbidden Phoenix, it is also a direct reaction to the structures which sought to ostracise early Chinese immigrants from the Canadian 
community (Gilbert and Tompkins, 1996) recounting the injustices practiced by institutionalized racism embodied in the character of Max Lochran, a Canadian government negotiator.

The play, highly influenced by cinema, is presented in an episodic format which bears a complex relationship to realism. Yee evokes in his play particular moments in history of racial injustices in an attempt to move from a "haunted past to a present with the potential to imagine a more generative future" (Miki 324). Like Chan, he uses counter-history to erase the effect of cultural trauma from contemporary Canadian thought and move towards reconciliation. However, Yee's lady in the red dress, does not stage a mythical hero. The play situates its characters in specific time slots analogous to key moments in Canada's immigration policies' timeline. The years 1923, 1943 and 2006 are not selected in an arbitrary manner; they are signs that correspond to actual events in Canada's history connecting the audiences through cues to a forgotten past that is still strongly felt in the present. The reference to these specific dates links the characters of the play and the events of the drama with the actual progression of events in Canada's broader scheme of immigration history (Chan, 2015). The events shift back and forth between the years 2006, 1923, 1943, and back to 2006. The fractured chronological structure of the play creates sufficient distance between audiences and the action of the play in order to evoke critical reflection on experiences that move them beyond their comfort zone.

In flashback, the audiences are transported to the year 1923. Tommy Jade an early Chinese immigrant worker is forced to pay $\$ 600$ as Head Tax, to Mr. Coogan, a government official, in order to allow him to bring his wife; however, they never unite. Eighty-three years later, it is Tommy's letter to his wife which provides evidence for the Chinese Canadian National Council of the back-door deal made with Mr. Coogan and his likes. The scene reminds audiences of the subtle discriminatory measures taken against Chinese immigrants in the past, and the absolute power yielded over them by government officials. Neither Marty Chan nor David Yee explicitly show the railroad or the early Chinese workers, however, their plays are dedicated to them; throughout the plays there are many implications that point to them. Tommy's letter reveals more than what Max Lochran a negotiator for the Canadian Department of Justice can possibly expect.

Sylvia, in lady in the red dress, is a half breed, serial killer who haunts those who have mistreated early Chinese immigrants over the years. She stalks them and slits their throats. Under the effect of narcotics and seduction, Tommy Jade, an early Chinese immigrant worker yields in to the government official's wife- Mirabel Coogan in his absence. Eight 
A Semiotic Reading of the East Asian-Canadian Restaging of the Immigrant Experience and Redress in Marty Chan's The Forbidden Phoenix and David Yees's lady in the red dress

months later, Coogan discovers that the baby girl (Sylvia) with whom his wife was pregnant is not his child; out of revenge he shoots Tommy dead. Tommy's blood spurts over the infant. Sylvia as an adult, is the embodiment of this horrific past; while she initially sets out to seek justice, her bloodied past is exemplified in her adorning a red dress and her determination for "Vengeance" (Yee 48). While Sylvia's main role is to bring national remorse over past injustices; she is at the same time a "deliberate rebuke to the China Doll trope" (Garebian) and a reflection of the Chinese Women's Movement. By today's measures, she is a political and social activist (Budde \&Taucar, 2011). Sylvia sends Max Lochran on a symbolic journey of redress and reconciliation through Chinatown pitted with cultural and linguistic barriers.

During his journey inside Chinatown to search for Tommy Jade, Max meets the brothers Happy Chan and Biff Chan; the first is a radio station presenter and the second a television floor director. Happy is offended when Max stereotypes him because of his last name. According to him, he's "the whole goddamn Pacific Rim," he is " $1 / 5$ Chinese, 1/7 Japanese, 3/8 Korean, 1/10 Filipino, 2/5 Taiwanese, 1/9 Laotian, 5/16 Mongolian and 3/4 Vietnamese" (Yee 44). Happy's immigrant identity deconstructs the notion of a "monolithic cultural heritage" (Chang 208). Biff is also later offended when Max claims he does not understand him "I'm sorry, can you not understand my accent? Do you want subtitles?" (Yee 66). Biff and Happy are the signifiers through which his journey to the past is connected. Happy connects Max through the radio frequency to talk to Tommy Jade. Biff through cable TV, connects Max to Tommy Jade. The past is too ugly for Max to bear. Biff warns Max: "You sure you want to keep watching this? You might not like what you see"(66). Max is traumatized to learn through the cable documentary that Tommy Jade had slept with his grandmother Mirabel Coogan in 1923 and together they conceived Sylvia a hybrid identity that seeks redress in 2006 for past injustices. Happy and Biff Chan serve as analogue models in order to connect Max with the past. According to Black's (1962) definition of signs which is aligned to Peirce and Saussure's, the "same structure or pattern of the relationship" (223) is identical but the change of medium is abstract. The journey into Chinatown is a journey to correct misconceptions and "righting a historical wrong" (Yee 30). The mediums through which Max is transported in his physical and emotional journey alternates between a dream, a radio frequency and cable TV. Reinforced with a pair of 3-D glasses. His connection to the past heightens his senses 
of hearing and seeing and opens his eyes to ugly and obscure facts. As he watches the documentary on cable TV, Max inquires about the opium used to drug Tommy in Coogan's home: "Did Tommy sell that, too? Biff "stalks over to MAX and takes the glasses off him" (Yee 68). Max tries to clarify: "I'm just saying, the Chinese trafficked opium into Canada, every-one knows that" (68). To which Biff responds: "Oh yeah?...Where do you grow opium? ... India. And who owned India in the nineteenth century? White people. The British. ... They enslaved the Chinese with opium, fought a war over it, took Hong Kong... and you say the Chinese brought opium to Canada? Who the fuck owned Canada? ... He throws the glasses back at MAX, who puts them on... Watch the goddamn show" (68).

At the start of his journey into Chinatown, Max's racial views are exposed. The Chinese coded ATM machine unnerves Max: “... I walk up and the screen, all the instructions, right ... they're in Chinese. They're in fucking Chinese. At the Royal Bank of Canada, Hatch. Of Canada, and it's in - I mean that's a symbol, it's a sign of - what is that- the times, or something ... They're taking over" (Yee 23). The ATM machine sign is further extended by making a reference to money. The whole play revolves around the Head Tax and "A "symbolic" twenty-three million, or "recognition" for the descendants" (Yee 22). Max as a model type, stands for Canadian government officials and represents their racial discrimination. He subsequently shares his view over a phonecall on redress with Linda the representative for the Chinese Canadian National Council: "Linda. Look, we are giving $\$ 20,000$ to each of the poor bastards that paid the tax. (beat). Around eight million in total. Yah, pretty big number, pretty generous number. I mean, let's not get carried away here, they paid $\$ 500$ each ... But it's not a numbers game, Linda, you have to understand that..." (Yee 7). The argument between Max Lochran and Linda over the government compensation as part of the redress is a sign in words. Language here is formulated of a "system of conventional signs and hence symbols" which evokes a mental image of the early Chinese immigrants and the struggle to reconcile with past injustices (Nöth 10).

Racial tensions in the play are further elucidated through the skillful use of language. Max Black (1962) explains that "in introducing a new language or dialect... Explicit or implicit rules of correlation are available for translating statements" and consequently a new domain is extended (229-30). Codified in Chinese, the ATM machine, according to Peirce and Saussure's theory of semiotics is an icon signifying the inherent Chinese culture which Max refuses to accept as part of Canada's heritage; it can also be interpreted as Max's in ability to immerse into the 
A Semiotic Reading of the East Asian-Canadian Restaging of the Immigrant Experience and Redress in Marty Chan's The Forbidden Phoenix and David Yees's lady in the red dress

Chinese cultural heritage in Canada. Language as a reflection of racial and discriminatory practices resurfaces again in two more instances, the first when Sylvia prompts Max to read Tommy Jade's letter to his wife which is written in Chinese. Coerced to read, Max is surprisingly able to decode the Chinese letters and reads the message: "Chor San. (English) Heh. That's weird, I can... (He continues in Cantonese.) Chor San... Yee gah hai hwoon yeah sam deem jung. Yut chay doo ting dunne sai. ... [Dear Love. It's three in the morning and life has stopped. I write to you, from the end of the world, from the edge of the horizon... only to tell you there is nothing beyond. Only emptiness" (Yee 31). The notion of language being deployed as a system of conventional signs and symbols is utilised by Yee in the reference to the Chinese language in the letter, the symbols on the ATM machine and during the conversation between Max and his cardiologist in the hospital. Max Lochran admitted to Toronto General Hospital after a heart attack is unable to comprehend the doctor's words. Unable to decipher the semiotic system of the Chinese language, Max is entrapped in his own prejudices against the man who can save his life:

Doctor: Excellent. Now if (He switches to Cantonese.) Yue goh yow leung gah foah cheh, joy tung yut see ghan, yow but tung goh foah cheh jam hoi cheut, keu - (Two trains leave from opposite stations moving at equal speed-)

Max: What? What did you say? ... English, can you say it in English?

Doctor: (in English) Mr. Lochran, I am speaking English. What are you hearing?

Max: I don't know. Gibberish, it sounds like ... (Yee 17-18)

The ineffective communication between Max and the Chinese doctor in this scene is a reference to the broader spectrum of disregard for the Asian community in Canada. Max's failure to comprehend the language and decode the language "symbols" reflects his denial of Canada's mixed cultural heritage and interculturalism. As a model type for all White Canadians and Government officials, he signifies the long standing reality of deliberately concealing historical realities which ultimately results in hindering redress. Additionally, the word play on "red dress" as a reference to "redress" allows Yee to situate his play in the present. By the time the play had been staged, redress payments had been made by the Government of Canada to Chinese Canadians who had paid the Head Tax, at least to those who were still alive. 
Unlike his autistic son, Danny, Max is unable to take advantage of the in-betweeness of hybridity. Danny, is a complicated, deranged and lonely autistic boy. He is unable to connect with his own father, signified by the drawing he made, a map of his father's office that is not scaled to the accurate measurements of the office space indicating the gap in perception and generation between the two (father and son). Ironically, Danny is able to bond with Sylvia who is a stranger to him over their mixed heritage as hapa (half Asian and half Canadian) while playing cards. The bonding with the lady in the red dress is significant. Danny is a second generation Asian-Canadian and Sylvia is the embodiment of the past injustices seeking vengeance and redress:

Danny: My half-and half card. My Queen of Sparts. Half-and half. Like me. Just like me.

Sylvia: Me too.

Danny: We're special.

Sylvia: We're mongrels. Mutts. We're ...less.

Danny: That's not what Max said. (Syliva scoffs) ... "Danny is twice blessed." The best of Max and the best of mother. Twice blessed. Like you. (Yee 84)

Danny's symbolic holding of the card in his hand, signifies that a winning co-existence between Canada's Caucasian roots and Asian heritage symbolically lays in the hands of second generation Canadians. On the other hand, Max Lochran's prejudice towards the Asian community is strikingly contrasted against this background throughout the play: "My wife's brother! Perfect example: working the rice paddies in China one minute, not a word of English, a quick boat ride later he's CFO of Merrill-fucking-Lynch...And I ' $m$ not being racist, here, I love Oriental girls!" (Yee 23). Max's lack of "superior cultural intelligence" and his denial of the historical roots of the Asian community in Canada, contrasts against the character of his son Danny who is a "cultural mediator" (Hoogvelt 158; Chang 36). Like Sylvia, Danny who is half Chinese and half Anglo-Canadian holds "a space between [his] maternal and paternal cultures" (Hoogvelt 158).

Similar to Chan's The Forbidden Phoenix, lady in the red dress is structured on "a different cultural basis of negotiation" which upholds a complex Chinese semiotic system of signifiers that speaks to second generation immigrants (Budde and Taucar 204). At the same time, the play is Canadian and speaks of the cultures that make up the nation. Audiences within such a complex system of signs and symbols are forced to consider the tensions of redress and the complexities of Canada's intercultural context. The Forbidden Phoenix by Marty Chan and David Yee's lady in the red dress both published in 2010 explore the tense 
A Semiotic Reading of the East Asian-Canadian Restaging of the Immigrant Experience and Redress in Marty Chan's The Forbidden Phoenix and David Yees's lady in the red dress

negotiations between settler Canadians and Chinese-Canadian immigrants. The plays bring together different time frames and are based on the notion of fluidity and interconnected temporalities. Both works reenact historical scenes from the past that revolve around confrontations between contemporary and significant historical events. The plays contribute through their unique complex semiotic systems and network of symbols ingrained in Chinese culture an "understanding of the difficult labour of active redress required on the part of White Canadians for rebalancing relationships" with Chinese-Canadians (Vellino 93). David Yee's lady in the red dress shows such an example where Max Lochran is forced to seek the encounter of Tommy Jade three subsequent times signified by different mediums before he is able to come to terms with the necessity of redress and understand the significance of Chinese immigrant experiences as part of Canadian history. According to Joanne Tompkins's (1995) theory of "infinite rehearsal" redress "may require repeatedly practiced encounters, wherein consolidated identities may be unframed, renegotiated, and restaged through an ongoing process" (142, 157-159). Max is forced to travel through China town to listen to and see the past through the experiences of the Other before the imbalance of power is shifted; the seeing and the listening are integral not only for rebalancing the dynamics of the Chinese-Canadian relationship but also integral to "substantive redress work" (Vellino 94). Like China town, the waterfall in Chan's play, signifies the passing through a cultural gateway to understand the misgivings of the past.

Both The Forbidden Phoenix and lady in the red dress use episodic structures that help unfold a sequence of confrontations between ChineseCanadians and White Canadians upholding "traditional practices and language revitalization as paths to cultural resurgence" (Keeptwo). The dramatic works "reinforce the intercultural collision of two worlds and time frames" (Vellino 94). At the same time, the characters bring back a haunting past to the present in order to reassert their "cultural endurance" (94) as well as show new generations of Asian - Canadians their "ethical responsibility to their community within a contemporary world still dominated by settler media constructions" (94). The culturally inherent structures of the two dramatic works examined invoke a rehearsal of past injustices that necessitate the practice of "internal self-reckoning as [a]... prerequisite for reclaiming ethical responsibility on the part of all of those caught in the uneven power dynamics" (95). Cantonese is also embedded 
in both plays as a symbol of lost truths, and an indicator of the act of being caught between two worlds.

The use of Chinese language as a semiotic system of signs is an indication of the nation's cultural blindness which is central to the message of both plays. Marty Chan and David Yee's plays should not be interpreted as plays show casing two parties clashing over a conflicting value system and past injuries; but rather both plays skillfully ghost the historic events of early Chinese immigrants building the CPR overlooked in Canada's historical narrative in order to reach reconciliation. The penultimate scenes in both plays send a hopeful message to second generation immigrants indicating that "public apologies" and calls for "revised historical memory" are acceptable "transitional justice" (Vellino 95; McEvoy and Mc Gregor 2-3) initiatives. According to Brenda Vellino (2017) Canada being a "settler state" has yet to take many measures to right previous wrongs and transform "conflicted relationships" (95). Theatres, within this context as David Garneau (2012) puts it can be used as "neutral spaces" which potentially serve as "spaces of conciliation" allowing performances such as The Forbidden Phoenix and lady in the red dress to rehearse practices of Chinese and Asian-Canadian "cultural sovereignty," and negotiate the "unlearning and new learning" necessary for building Canada as a nation (35-37). Theatre in this regard can enforce much welcomed unofficial interventions necessary for the many stages of redress. Peter Cockett, a theatre director, further explains that such performances promote a healthy reappraisal of the past suffering of Chinese-Canadians and invite us to acknowledge past injustices before we can speculate on how Canada came to be the country it is today.

Largely read as railroad-plays, Marty Chan's The Forbidden Phoenix (2010) and David Yee's lady in the red dress (2010) have not been examined for the robust semiotic system on which they have been designed. The analysis in this paper has focused primarily on the exploration of the use of semiotics in these two award winning East Asian Canadian plays. Both plays are Chinese plays told in a Western style. Both works highlight critical issues such as immigration, hybridity, racial discrimination and the importance of acknowledging past injustices in order to reach redress in a multicultural Canada. More importantly, the plays contain three basic features: "first, the presence of a Chinese immigrant as protagonist or principle character, often portrayed within familial contexts; secondly, the recollection of social injustice and discrimination experienced by Chinese immigrants; and finally, a clear movement towards reconciliation through the reenacting of history and its connection to an evolving present condition" (Chang 198). The cultural and linguistic signifiers embedded in the plays referring to the early 


\section{A Semiotic Reading of the East Asian-Canadian Restaging of the Immigrant Experience and Redress in Marty Chan's The Forbidden Phoenix and David Yees's lady in the red dress}

Chinese immigrants' experiences remarkably transcend national borders. Despite the success of these two dramatic works, it would be "wrong to suggest that East Asian Canadian theatre has developed across Canada," Marty Chan explains that "in the centres outside Toronto and Vancouver, the scene is small or in some cases, non-existent" (Interview with Marty Chan, 2018). Examined in light of Saussure's and Peirce's theory of semiotics, the two plays present historical national injustices faced by early Chinese immigrants with a contemporary perspective that is forward moving and deeply reflective. Both plays reenact a historical scenario of negotiations over past injustices that are underpinned with intercultural depictions signified through an intricate semiotic system that masterfully engages its audiences in a transporting process of encoding and decoding of meaning.

\section{Acknowledgment}

I would like to thank playwright Marty Chan for the time he dedicated for the personal interview. 


\section{Rania Mohamed Rafik AbdelFattah Khalil}

\section{Works Cited Page}

Al-Sheikh Hussein, Basel. "The Sapir-Whorf Hypothesis Today." Theory and Practice in Language Studies, vol. 2, no. 3, Academy Publisher, 2012, pp. 642-46. Semantic Scholar, DOI:10.4304/tpls.2.3.642-646 www.semanticscholar.org/paper/The-Sapir-Whorf-Hypothesis-TodayBasel-Hussein/f34f8988e2b01a13e4474e4374dc00d00ed4317a

Budde, Antje and Jacqueline Taucar. "China Doll: A Conversation with the Canadian Playwright Marjorie Chan." Canadian Review of Comparative Literature, vol.38, no.2, Canadian Comparative Literature Association, 2011, pp.201-213.

Barwise, Jon and John Perry. Situations and Attitudes. Center for the Study of Language and Information, MIT Press, 1983.

Berger, Arthur. "Semiotics and Society." Society, vol. 51, no.1, 2014, pp.2226. Semantic Scholar, DOI:10.1007/s12115-013-9731-4 www.semanticscholar.org/paper/Semiotics-and-SocietyBerger/78756c3026ffdc826ee309b9879584c6cab4513b

Berton, Pierre. The Last Spike: The Great Railway, 1881-1885. McClelland and Stewart Limited, 1971.

Bhabha, Homi. Nation and Narration. Routledge, 1990.

-. The Location of Culture: Discussing Post-Colonial Culture. Routledge, 1994.

Chan, Marty. About Marty Chan. 2018. 3 June 2018 <http://martychan.com/books/theatre/the-forbidden-phoenix/>.

-.Historical Changes in East Asian Canadian Theatre - Interview with Marty Chan Rania M Rafik Khalil. 21 May 2018.

—. The Forbidden Phoenix. Playwright Canada Press, 2010.

Chang, Eury. Railroad Plays: Performing Reconciliation in Asian North American Theatre. 2002.University of British Columbia, MA Thesis.

—. "Towards Reconciliation: Immigration in Marty Chan's The Forbidden Phoenix and David Yee's lady in the red dress." Theatre Research in Canada, vol.36, 2015, pp.196-215. Questia www.questia.com/library/journal/1G1-435636747/towardsreconciliation-immigration-in-marty-chan-s.

Courtney, Richard. Play, Drama and Thought: The Intellectual Background to Dramatic Education. Simon \& Pierre Pu, 1989.

Filewod, Alan. Performing Canada: The Nation Enacted in the Imagined Theatre. University College of the Cariboo Print Services, 2002.

Garebian, Keith. A Performing and Literary Arts Review. 1607 2018. 23 July 2018 www.stageandpage.com/bookreviews.htm\#bookreviews-top.

Gilbert, Helen and Joanne Tompkins. Post-Colonial Drama: Theory, Practice, Politics. Routledge, 1996.

Gilbert, Sophie. Scene: Moonlight. 26 December 2016. 29 June 2018, www.theatlantic.com/entertainment/archive/2016/12/the-power-ofwater-in-moonlight/511547/ 
A Semiotic Reading of the East Asian-Canadian Restaging of the Immigrant Experience and Redress in Marty Chan's The Forbidden Phoenix and David Yees's lady in the red dress

Gilodo, Karen and Christina Sangalli. Theatre for Young People - The Forbidden Phoenix. Theatre for Young People, 2009.

Hall, Stanley . The Dream. 27 March 2016. 28 June 2018, www. ebooks.adelaide.edu.au/f/freud/sigmund/general-introduction-topsychoanalysis/chapter10.html.

"History." Building the Canadian Pacific Railway. 9 September 2005. 13 June 2018 www.collectionscanada.gc.ca/settlement/kids/021013-2031.3e.html.

Hoogvelt, Ankie. Globalisation and the Postcolonial World:The New Political Economy of Development. John Hopkins University Press, 2001.

Jenkinson, Dave. Marty Chan. 4 March 2009. 17 June 2018 www.cmreviews.ca/cm/profiles/chan.html

Keeptwo, Suzanne. NAC English Theatre - The Edward Curtis Project. 2012. 22 December 2018 nac-cna.ca/en/englishtheatre/studyguide/the-edwardcurtis-project.

Krieger, Nancy. "Embodying Inequality: A review of concepts, measures, and methods for studying health consequences of discrimination." International Journal of Health Services, vol. 29, no.2 1999, pp.295352. National Center for Biotechnology Information www.ncbi.nlm.nih.gov/pubmed/10379455. DOI: $\quad$ 10.2190/M11WVWXE-KQM9-G97Q

Lanir, Lesley. Ferdinand de Saussure: The Linguistic Unit - Sign, Signified and Signifier Explained. 27 November 2012. 16 June 2018. www.decodedscience.org/ferdinand-de-saussure-the-linguistic-unitsign-signified-and-signifier-explained/20876.

Lutterbie, John. "Transforming Gesture to Sign in the Theatre." ARTIGO Revista Digital de Technologias Cognitivas, 2010, pp.37-48. 16 June 2018.

www.pucsp.br/pos/tidd/teccogs/edicao_completa/teccogs_cognicao_info rmacao-edicao_4-2010-completa.pdf

Marx, Leo. "The Railroad in the Landscape: An Iconological Reading of an American Theme." The Railroad in American Art. MIT Press, 1988, pp. 183-206.

McEvoy, Kieran and Lorna McGregor. "Transitional Justice From Below:An Agenda for Research, Policy and Praxis?" Human Rights Law In Perspective: Transitional Justice From Below, Grassroots Activism and the Struggle for Change, Edited by Kieran McEvoy and Lorna McGregor. Hart, 2008, pp. 1-25.

Meerzon, Yana. "Theatre and immigration: From the Multiculturalism Act to the Sites of Imagined Communities." Theatre Research in Canada, vol.36, no.2, 2015, pp.181-195. 16 June 2018. www.journals.lib.unb.ca/index.php/TRIC/article/view/24302 


\section{Rania Mohamed Rafik AbdelFattah Khalil}

Miki, Roy. "By Turns Poetic: Redress as Transformation." Rogers, Shelagh, Mike DeGagne and Jonathan Dewar. Speaking the Truth : Reflections on Reconciliations and Residential School. Aboriginal Healing Foundation, 2012, pp.205-217.

MTCSALTC - The Metro Toronto Chinese \& Southeast Asian Legal Clinic Government of Canada. The legal struggle for equal rights of Chinese Canadians. 2011. 12 June 2018 www.roadtojustice.ca/laws/chinesehead-tax.

Mukařovsky, Jan. "'L'arte come fatto semiologico'.English trans. in Matejka and Titunik (1976)." Ill significato dell' estetica. Einaudi, 1934, pp.141-8.

Noth, Winfried. "The semiotics of models." Sign Systems Studies, vol. 46, no.1, 2018, pp.7-43.

Pierce, Charles. On Signs: Writings On Semiotic, Edited by James Hoopes. North Carolina University Press, 1991.

Playwrights Canada Press. David Yee. 2016. 15 July 2018 www.playwrightscanada.com/index.php/david-yee.html.

Posner, Roland. "Basic Tasks of Cultural Semiotics." Signs of Power - Power of Signs. Essays in Honor of Jeff Bernard, Edited by Gloria Withalm and Josef Wallmannsberger. INST, 2004, pp. 56-89 online (1-41). 12 June, 2019. faculty.georgetown.edu/irvinem/theory/Posnerbasictasksofculturalsemiotics.pdf

Regehr, Theodore . VAN HORNE, Sir WILLIAM CORNELIUS. 1998. 15 June 2018 www.biographi.ca/en/bio/van_horne_william_cornelius_14E.html.

Rojas, Carlos. "Western Journeys of Journey to the West." Hayot, Eric, Huan Saussy and Steven Yao. Sinographies:Writing China. University of Minnesota Press, 2008, pp.3335-354.

Salis, Loredana. Stage Migrants: Representations of the Migrant Other in Modern Irish Drama.Cambridge Scholars Publishing, 2010.

Sherridan, Sherri. Creating Original Characters, Themes, and Visual Metaphors for Your Digital Short Film. 9 July 2004. 29 June 2018. www.peachpit.com/articles/article.aspx? $\mathrm{p}=174318 \&$ seqNum=3.

Standford University . Chinese Railroad Workers in North America Project. 2018. 13 June $2018<$ http://web.stanford.edu/group/chineserailroad/cgibin/wordpress/faqs/>.

Stanley, Timothy. "By the SIde of Other Canadians: The Locally Born and the Invention of Chinese Canadians." BC Studies, vol.156, 2007, pp. 109139.

Streeton, Jane and Philip Raymond . Singing on Stage: Acting Through Song. 2018.

www.actorsandperformers.com/actors/advice/138/training-andskills/drama-schools.

The Railroad Network. Trains in Literature. 2011. 2 July 2018 www.railroad.net/articles/topics/trains-in-literature.php. 


\section{A Semiotic Reading of the East Asian-Canadian Restaging of the Immigrant Experience and Redress in Marty Chan's The Forbidden Phoenix and David Yees's lady in the red dress}

Tompkins, Joanne. "'The Story of Rehearsal Never Ends': Rehearsal, Performance, Identity in Settler Culture Drama." Canadian Literature, vol.144, 1995, pp.142-61.

Toronto Theatre Database. lady in the red dress. 18 July 2018. 22 July 2018 www. ttdb.ca/shows/lady-in-the-red-dress.

Vellino, Brenda. "Restaging Indigenous - Settler Relations: Intercultural Theatre as Redress Rehearsal in Marie Clements's and Rita Leistner's The Edward Curtis Project." Theatre Research in Canada vol.38, no.1, 2017, pp. 92-111.

Veltrusky, Jiri, Tomas Hoskovovec and Jarmila Veltrusky. An Approach to the Semiotics of Theatre. Masarykova Univerzita, 2012.

Vision Times. What Do the Masks Represent in Chinese Opera? 20 June 2017. 17 June 2018 www.visiontimes.com/2017/06/20/the-secret-of-masks-inchinese-opera.html.

Yee, David. lady in the red dress. Playwrights Canada Press, 2010.

Zabel, Ann. "Two trains running": The train as symbol in twentieth-century African American literature"." PhD Dissertation. Ann Arbor, January 2001. 